\title{
Una perspectiva estructural para comprender los problemas económicos
}

Frases alrededor de cómo entramos y cómo salimos de la crisis, acerca de si hay o no hay signos de recuperación económica, sobre cómo mejora o no la confianza del consumidor, alrededor de la pérdida de empleos y la caída del dólar, y otras similares - todas ellas relacionadas con cuestiones coyunturales propias del ciclo económico-, ocupan no sólo los titulares de los principales periódicos y medios de comunicación, sino también acaparan las revistas especializadas en temas propiamente económicos o empresariales, y en la mente de analistas, empresarios y ciudadanos el momento y la inmediatez de los acontecimientos supuestamente importantes desde el punto de vista económico, deja de lado lo fundamental del desenvolvimiento de la economía.

Si cuando inició la economía, los análisis eran esencialmente estructurales, en la actualidad, estos se quedan en un abordaje meramente coyuntural. Esta transformación tan radical del análisis económico dio inicio con el advenimiento de los análisis marginales y con el empeño 
de elevar la categoría de la economía a ciencia, la más científica dentro del espectro de ciencias sociales, para ello se desarrolló un amplio instrumental matemático y una fina elaboración. Pero estos modelos cada vez más sofisticados y rigurosos perdieron poco a poco el anclaje con la realidad, esta que día a día reelaboran las personas al relacionarse en todo sentido: político, económico, social, cultural, sentimental.

Hoy en día la información fluye como nunca antes fue posible, y la disponibilidad de información y de datos es casi infinita. Por lo mismo están disponibles una gran cantidad de modelos matemáticos que manejan variables que van desde los vaivenes de las acciones de una empresa de microchips, para las cuales las tormentas eléctricas del hemisferio norte influyen, hasta variables más cualitativas y agregadas ( $i !)$ como la confianza en el futuro que poseen los consumidores de un país dado, o el nivel de felicidad promedio de la población.

Los análisis económicos compiten por predecir el futuro, aunque éste no existe todavía, mientras que del pasado lo único que interesa son las pérdidas o ganancias económicas que pudo dejar, y la información útil para pronosticar cómo subirá o bajará el tipo de cambio del dólar con respecto al euro o si el crecimiento económico avanzará o retrocederá. Muy pocos, escasos son los análisis que dejan de lado el vertiginoso presente y el esquivo futuro para enfocarse en temas más bien estructurales, estos que buscan develar relaciones entre instituciones y actores de la vida económica, social, cultural, incluso ambiental de un país. El objetivo de este tipo de análisis es entender las causas de los pobres resultados en términos de equidad y bienestar para la mayoría de las personas, tanto a nivel mundial pero sobre todo a nivel nacional, para también pensar en alternativas más equilibradas en la distribución de los frutos del trabajo humano.

En esta revista se presentan una serie de escritos que abordan temáticas socioeconómicas y ambientales que buscan lograr análisis más estructurales y menos coyunturales, que además aborden temas de interés para el bienestar de la población en general. Cada uno de ellos presenta una vista de la situación actual, un análisis de mediano plazo bajo un marco conceptual determinado y explicado, y una suerte de conclusiones y propuesta de alternativas.

Las temáticas abordan los problemas de inequidad que devienen en desequilibrios de todo tipo: territoriales, generacionales, de género o entre clases sociales por mencionar algunos. En los análisis intentan desviar el enfoque que insistentemente atribuye estos resultados a la coyuntura 
regional y mundial, o a la manera en que se ha organizado el modelo económico actual o la ejecución o no de determinadas políticas públicas del gobierno de turno, y buscar otras explicaciones más estructurales e históricas.

Todos conocemos sobre la desigualdad que padece el país, pero pocos conocemos sobre las causas que fortalecen las desigualdades en los ingresos y en las capacidades de consumo de los y las salvadoreñas. La múltiples exclusiones que se fortalecen y retroalimentan mutuamente para configurar una situación de inequidad, por ejemplo el desigual acceso en calidad y cantidad a la educación y salud, la concentración de la tierra y de otros activos productivos, el desigual acceso a mercados financieros y laborales formales, y la mala redistribución a través del estado a su vez pueden explicarse en parte por medio de dos causas estructurales: la falta de vinculación entre los sectores o heterogeneidad estructural y los problemas de productividad que dificultan la inserción de la economía regional en relaciones no asimétricas y desventajosas.

Es curioso que a pesar de la trascendencia de la heterogeneidad estructural que sufre el país, no solo debido a su importancia como un obstáculo estructural a la equidad sino también al logro de una mayor eficiencia y acumulación económica para el país y los sectores productivos, ésta no haya sido medida por algún organismo gubernamental o privado salvadoreño. Un intento de medición utilizando la composición del mercado laboral según niveles de empleo, subempleo y desempleo, la actividad económica sectorial y los niveles de formalidad e informalidad; y su relación con lo niveles de desigualdad permite revalidad la hipótesis que el fenómeno de la desigualdad afecta y es afectado por la estructura productiva.

Este análisis permite enfatizar la importancia de dos cosas: a) que en El Salvador se promueva una dinámica de desarrollo hacia dentro, en oposición a lo que se recomienda usualmente por los organismos nacionales e internacionales. Se necesita primero dinamizar las ramas de actividad económica que generan más valor agregado, las del sector primario y secundario con producción real, de ser posible dirigida al mercado interno; b) que el principal problema de la dinámica ocupacional del país no es el desempleo, sino el crecimiento sistemático de la informalidad y el subempleo relacionado con la heterogeneidad estructural. Si se toma en cuenta el literal a) precedente se logrará mejorar el problema de la precarización de los y las trabajadoras del país. 
Por otro lado, la estructura laboral se analiza a la luz de los diferentes modelos económicos que han implantado en el país, es por esto que se lleva a cabo un examen de cómo cada uno de estos modelos (agroexportador basado en el café, o agroexportador con impulso a la industria manufacturera y el terciario-maquilero) se vincula con la estructura laboral en cada período, a través de una movilización en tres sentidos; cualitativa manifestada por medio del cambio en el perfil educativo de la población trabajadora, geográfica a través de la concentración poblacional en zonas económicamente dinámicas e intersectorial, exteriorizada por medio del traslado actividades por ejemplo agrícolas a industriales (de lo rural a lo urbano). A pesar de esta movilización de la fuerza de trabajo, una constante en el país es la incapacidad de los sectores productivos privados de proveer la cantidad y calidad suficiente de puestos de trabajo. Esta situación lleva a que las personas se involucren en actividades productivas fuera de los circuitos formales de la economía capitalista o al margen de ésta, resultando en una sobreexplotación de la fuerza de trabajo, y esta realidad de la mayoría de la población salvadoreña se convierte en una fuente de acumulación y ganancia extraordinaria y acumulación para los sectores dinámicos del país en cada período.

Esta movilización y localización de la actividad económica y de la fuerza de trabajo, en gran parte da cuenta de los profundos desequilibrios territoriales que expresa el país. Aunado a lo anterior y debido a los tipos de modelos económicos se que se han impulsado, El Salvador padece de una desarticulación sectorial y de una heterogeneidad productiva; la primera se refiere a la incapacidad de la economía de producir efectos en cadena de todos los sectores económicos, y la segunda a la escasa vinculación productiva entre diferentes empresas. Esta situación se ha profundizado con la desnacionalización, privatización y apertura a la inversión extranjera que ha dominado al país. Pero es posible mejorar esta situación fomentando lo siguiente: a) una mayor cobertura y mejor calidad de la educación, salud y servicios básicos, b) una economía solidaria o social (en contraposición a la capitalista o privada), c) el ordenamiento territorial y la provisión de vivienda e infraestructura de transporte d) la seguridad y soberanía alimentaria.

Esta última, la soberanía alimentaria está afectada tanto por el cambio climático que padece el planeta, como por la producción de la agrocombustibles a nivel regional y mundial. Para ambos fenómenos, el modelo de crecimiento económico mundial fundamentado en un exceso de consumo de energía deriva por un lado en la generación de Gases de Efecto Invernadero (GEI) por encima de lo que permite el equilibrio del sistema 
climático, y por otro en el agotamiento de las reservas de combustibles fósiles. Este exceso expulsión de GEI ha derivado en un cambio climático que implica variaciones en los patrones pluviales, en las temperaturas y en otras variables climáticas. Para el sector agrícola estos cambios llevan a mayores pérdidas por eventos climáticos y una reducción en los rendimientos, por lo mismo en una reducción de la oferta de alimentos, si a esto le sumamos la utilización de algunos alimentos como la soja, el maíz, el azúcar para la producción de agro combustibles, sin duda la seguridad alimentaria se ve amenazada, tanto en la disponibilidad de los alimentos como en el acceso económico a los mismos.

Poco puede hacer el país para revertir estos fenómenos, pero sí puede llevar a cabo medidas de adaptación para el sector agrícola que van desde medida en infraestructura, agronómica hasta gubernamentales como las gestiones estatales y ciudadanas para el correcto uso del suelo y manejo de cuencas hidrográficas importantes y zonas costeras vulnerables a inundaciones, reforestación conjunta entre gobierno central, local y ciudadanía de cuencas hidrográficas entre otros.

Dentro de los problemas para lograr una seguridad alimentaria la disponibilidad resulta ser el menos grave, pues las carencias en producción, hasta el momento se han logrado cubrir con importaciones. Sin embargo, esta disponibilidad puede verse amenazada por la producción de agro combustibles. Es el acceso la dimensión más sensible para la población salvadoreña, este se manifiesta sobre todo a través de la subnutrición y desnutrición de amplias capas de la población. Existe también un riesgo de inestabilidad alimentaria debido a la falta de continuidad en las políticas a largo plazo relacionadas con la seguridad alimentaria y la falta de conservación de los recursos naturales, y la posible competencia de los agro combustibles.

Todos los problemas que se hemos citado hasta el momento se ven influenciados o potenciados por la apertura comercial que el país ha experimentado en las últimas décadas. La lógica de todos los gobiernos, desde la firma de los acuerdos de paz, para apostar por ella está sustentada en que apoya el crecimiento, sin embargo, a pesar que en El Salvador se llevó a cabo una reforma estructura que incluyó una apertura comercial, el país no ha logrado obtener tasas altas y sostenibles de crecimiento. La tendencia estructural al deterioro de la balanza comercial es determinante en los factores que determinan la relación entre la apertura comercial y el pobre crecimiento económico. Otro tanto podemos decir de la estrecha relación del país con Estados Unidos, principal socio 
comercial con quien mantiene una relación estrecha de crecimiento económico en el largo plazo.

En El Salvador, el proceso de apertura externa ha fracasado en lo que concierne a disminuir o revertir la tendencia deficitaria en los saldos comerciales, más bien la ha profundizado. Esta tendencia resulta insostenible en el largo plazo, debido a la creciente necesidad de divisas (dólares) para mantener el ritmo de las importaciones. Por otra parte, el intercambio comercial ha dejado pérdida con una clara tendencia al incremento. Es decir, la apertura comercial no ha funcionado, lejos de ellos ha colocado al país en una situación de mayor vulnerabilidad. Posiblemente los negociadores de los tratados negociados y firmados no tuvieron en cuenta canastas de bienes que permitan potenciar el beneficio para el país, posiblemente debido a la falta de estudios estructurales que evidenciaran cuáles son los bienes y servicios que deberían negociarse tanto en nuestro mercado como en de nuestros socios comerciales.

Estas temáticas son una muestra de la gran variedad de asuntos que pueden y deben ser analizados desde una perspectiva más estructural y menos matematizada, permitiendo a las ciencias sociales, en especial a la economía, dejar un poquito lo meramente circunstancial y hacer un intento por adentrarse a las estructuras creadas por los seres humanos, por lo mismo, modificables si es que se conocen o se entiende qué es lo que está pasando y qué se puede hacer para mejorar la situación de bienestar.

Esta número espera colocar perspectivas poco usuales, y lograr espacios de pensamiento diferentes a los dominantes, que finalmente lleven a cuestionar lo actuado como sociedad para cambiar el rumbo, aunque estamos claros que lo más difícil no es escuchar o leer nuevas perspectivas sino interiorizarlas de tal manera que lleven a un cambio en el actuar, pues como dice John Maynard Keynes La dificultad radica, no en las nuevas ideas, sino en escapar de la antiguas, las cuales están ramificadas para aquellos que han sido criados como la mayoría de nosotros, en cada rincón de nuestras mentes ${ }^{1}$.

1 Citado por Gárate, Tablas y Urbina al inicio del texto. 